Review

\title{
The Landscape of Regulatory Noncoding RNAs in Ewing's Sarcoma
}

\author{
Connor Barrett, Anuj Budhiraja, Vijay Parashar and Mona Batish *[D \\ Department of Medical and Molecular Sciences, University of Delaware, Newark, DE 19716, USA; \\ cbarrett@udel.edu (C.B.); anujbmt124@gmail.com (A.B.); parashar@udel.edu (V.P.) \\ * Correspondence: batish@udel.edu; Tel.: +1-30-2831-8591
}

Citation: Barrett, C.; Budhiraja, A.; Parashar, V.; Batish, M. The Landscape of Regulatory Noncoding RNAs in Ewing's Sarcoma. Biomedicines 2021, 9, 933. https:// doi.org/10.3390/biomedicines9080933

Academic Editor: Arnab Ghosh

Received: 22 June 2021

Accepted: 27 July 2021

Published: 31 July 2021

Publisher's Note: MDPI stays neutral with regard to jurisdictional claims in published maps and institutional affiliations.

Copyright: (c) 2021 by the authors. Licensee MDPI, Basel, Switzerland This article is an open access article distributed under the terms and conditions of the Creative Commons Attribution (CC BY) license (https:// creativecommons.org/licenses/by/ $4.0 /)$.

\begin{abstract}
Ewing's sarcoma (ES) is a pediatric sarcoma caused by a chromosomal translocation. Unlike in most cancers, the genomes of ES patients are very stable. The translocation product of the EWS-FLI1 fusion is most often the predominant genetic driver of oncogenesis, and it is pertinent to explore the role of epigenetic alterations in the onset and progression of ES. Several types of noncoding RNAs, primarily microRNAs and long noncoding RNAs, are key epigenetic regulators that have been shown to play critical roles in various cancers. The functions of these epigenetic regulators are just beginning to be appreciated in ES. Here, we performed a comprehensive literature review to identify these noncoding RNAs. We identified clinically relevant tumor suppressor microRNAs, tumor promoter microRNAs and long noncoding RNAs. We then explored the known interplay between different classes of noncoding RNAs and described the currently unmet need for expanding the noncoding RNA repertoire of ES. We concluded the review with a discussion of epigenetic regulation of ES via regulatory noncoding RNAs. These noncoding RNAs provide new avenues of exploration to develop better therapeutics and identify novel biomarkers.
\end{abstract}

Keywords: Ewing's sarcoma; noncoding RNAs; microRNAs; long noncoding RNAs; regulatory RNAs; tumor progression; epigenetics; biomarkers; therapeutic targets

\section{Introduction}

Ewing's sarcoma (ES) primarily results in tumors of the bone or surrounding tissue and belongs to a larger group deemed Ewing's sarcoma family tumors, which also includes peripheral primitive neuroectodermal tumors that affect mostly soft tissues [1,2]. ES accounts for roughly $10 \%$ to $15 \%$ of bone tumors and is the second most common malignant bone cancer in children [3]. Most ES cases occur between the ages of 15 and 20, with a slightly higher incidence in males [4]. Intermittent pain is a common symptom that tends to be first overlooked given the commonality of concurrent histories of trauma in children and adolescents, which may complicate and delay the diagnostic process [5]. Patient survival rates in localized cases are around 70\% after five years but fall sharply to $30 \%$ after ten years and just $25 \%$ after five years if metastasis is present at diagnosis [6].

In $90 \%$ of cases, the onset of tumorigenesis is the fusion of the Ewing sarcoma break point region 1 (EWSR1) and Friend leukemia intergenic (FLI1) genes following a reciprocal translocation event [6]. EWSR1 codes for an RNA-binding protein and is originally found on chromosome 22, while the FLI1 proto-oncogene codes for a transcription factor and is originally located on chromosome 11. Translation of the fused genes results in a single chimeric product called EWS-FLI1, which contains the N-terminal transcription-activating domain of EWSR1 and the C-terminal DNA-binding domain of FLI1 [7]. EWS-FLI1 alters the expression of many genes involved in metabolic pathways and cell development, and it is the main oncogenic driver for ES [6,8]. Exploring mechanisms of action of ES remains an active field [9]. Significant research initiatives have pursued the identification of pathways in which EWS-FLI1 is involved in and the role of non-genetic/epigenetic contributors to 
these events [10-12]. Characterization of these epigenetic regulators, including noncoding RNAs, presents a promising new direction for future endeavors [13].

In this review, we aim to explore the role of regulatory RNAs in ES. A more thorough understanding of epigenetics could begin to explain why population-level differences (e.g., between European and African populations) exist and account for varied effects on the clinical level of treatment. Our comprehensive review of noncoding RNAs (ncRNAs) in ES covers primarily microRNAs (miRNAs) and long noncoding RNAs (lncRNAs); because other noncoding RNAs are not yet characterized for their role in ES. We based the structure of our literature search on the PRISMA 2020 statement flowchart design for systematic reviews (Figure S1). Though intended for systematic reviews, this flowchart was helpful in organizing search results. The numbers of included and excluded publications for each step are listed. We also include a report of initial keyword search results from PubMed in Table S1. Notably, other types of ncRNA like circular RNAs and piwiRNAs have been studied in the closely related osteosarcoma [14,15], but we were unable to locate any relevant publications linking them to ES; tRNA fragments and eRNAs have also been discovered in cancers other than ES [16-18]. Here, we present current understanding on the tumor suppressor roles of miRNAs, the oncogenic activity of both miRNAs and lncRNAs and the interplay between these two classes of ncRNAs in ES. The schematic of current state of knowledge and missing gaps is summarized in Figure 1.

(a) Epigenetic regulation

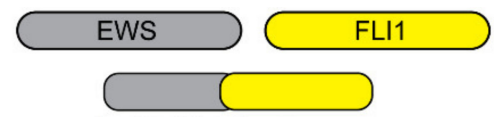

(b) Feedback Loops
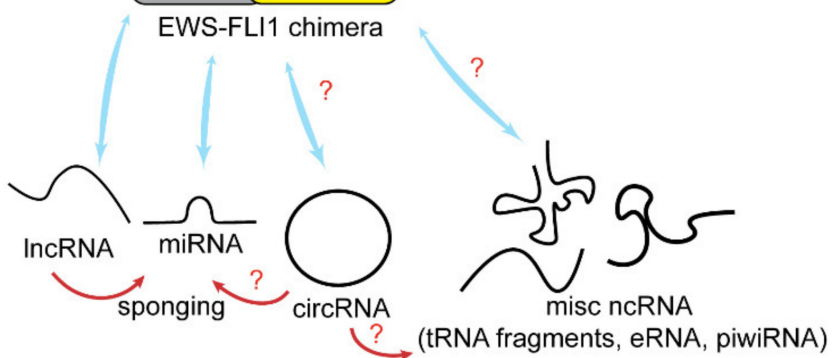

(d) Roles of ncRNAs

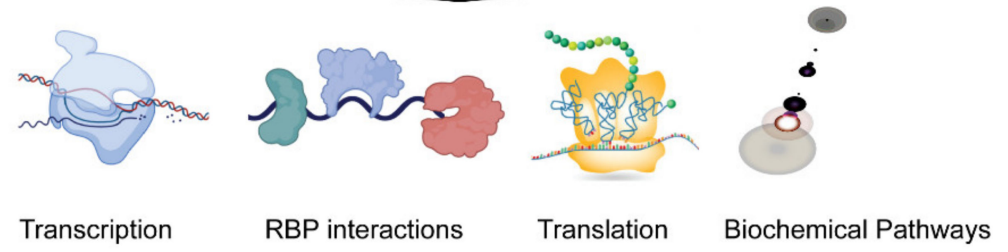

Figure 1. Noncoding RNAs and ES. (a) A chimeric fusion product of EWS and FLI1 genes, EWSFLI1, exerts epigenetic control by regulating the expression of different classes of ncRNAs (shown as blue arrows). (b) Some ncRNAs also alter the expression of EWSFLI1 as a means of feedback regulation of their own expression levels. (c) ncRNAs have an extensive interplay between each other (shown as red arrows). (d) ncRNAs play roles in regulating transcription, RNA export and transport. They interact with different RNA binding proteins (RBPs), translation and modulating signaling pathways. Red question marks indicate unknown and yet to be explored connections.

\section{MicroRNAs}

\subsection{Biogenesis and Function of MicroRNAs}

MicroRNAs (miRNAs) are a specific type of noncoding RNA (ncRNA) averaging 22 nucleotides in length that play key functions in the epigenetic regulation of a variety of human processes and several cancers [19]. A number of pathways have been identified for the biogenesis of miRNAs. Briefly, there are four main steps in the biogenesis of miRNAs in the most well established canonical pathway [20]. In the first step, RNA polymerase II synthesizes long stem-loop structures called primary miRNAs (pri-miRNA) that have 
stable 7-methylguanosine caps and poly-(A) tails. In the second step, a microprocessor complex consisting of Drosha and associated factors like DiGeorge critical region 8 (DGCR8) interacts with the stem loop regions of the pri-miRNA and cleaves it into $\sim 70$ nucleotide long single hairpins called precursor miRNAs (pre-miRNAs). In third step, the pre-miRNAs are exported to the cytoplasm via exportin 5 (exp5), and the combination of Dicer and transactivation-response RNA binding protein (TRBP) cleaves them further into 21 nucleotide dsRNA duplexes. In the fourth step, an RNA-induced silencing complex (RISC) including an argonaute protein (AGO), results in one strand of miRNA being discarded, while the other remains with AGO as the mature functional miRNA product [21].

Usually miRNAs bind to the $3^{\prime}$ untranslated region (UTR) of target mRNA sequences, which results either in the degradation of target mRNA, or in the inhibition of translation of the target mRNA, thereby reducing gene expression [22]. MiRNAs act in a variety of biological pathways required for normal function including nervous system development, stem cell differentiation, angiogenesis and reproduction [23-26]. Previous reviews have indicated the ubiquity of miRNAs in a variety of sarcomas ranging from osteosarcoma, rhabdomyosarcoma, liposarcoma and many more. The dysregulation of cell cycle pathways, dysregulation of apoptosis, dysregulation of stemness and increased proliferation/migration/invasion tend to be the regulatory mechanisms pertinent to oncogenic miRNAs in sarcomas [27-29]. As with other cancers, certain miRNAs in ES are downregulated if they normally play a tumor suppressive role, while others are upregulated if they have oncogenic functions.

\subsection{Tumor Suppressor miRNAs}

The microRNAs whose normal expression in the cell is required to maintain the physiological states of the cell in terms of regulated cell growth and apoptosis are called tumor suppressor miRNAs. Some of these miRNAs are also involved in regulating the expression of oncoproteins. Here we describe a few of such tumor suppressor miRNAs reported to play tumor suppressive roles in ES. Ultimately, a plethora of studies showed several key examples of miRNAs that play protective roles, and downregulation of their expression often leads to progression of ES at the cellular level.

\subsubsection{Let-7a and Associated miRNAs}

A group of three miRNAs-let-7a-2-3p, 16-2-3p, and 29b-1-5p-is involved in an oncogenic loop with c-Myc and cyclin-D2 (CCND2) [30]. This is consistent with the established role of cell cycle regulation in preventing tumorigenesis [31]. Both c-Myc and CCND2 were found to be overexpressed in ES-derived cell lines, and it was subsequently found that c-Myc negatively regulates all three miRNAs, while CCND2 is the downstream target. This oncogenic loop illustrates how miRNA connects regulators and targets. In ES, the c-Myc pathway along with the spleen tyrosine kinase (SYK) pathway can promote the transcription of the long noncoding RNA metastasis associated lung adenocarcinoma transcript 1 (MALAT1) [32,33]. MALAT1 has a variety of oncogenic functions in many cancers including breast cancer to renal cell carcinoma and often correlates with decreased survival rates [33]. In non-cancerous cells, let-7a-2-3p, 16-2-3p, and 29b-1-5p also act to suppress oncogenesis by retarding the cell cycle at G0/G1 [30]. The robustness of this miRNA group's tumor suppressor model was further tested by an ex vivo quantification of tumor size in mouse xenograft models, which further confirmed the tumor suppressor effects of these miRNAs [30]. Let-7a itself also acts in an additional regulatory axis with signal transducer and activator of transcription 3 (STAT3) and phospho-NF-KB p65 (p-P65) to inhibit carcinogenesis, including control over macrophage infiltration [30]. STAT3 was shown to be a target of let-7a, and STAT3 inhibition resulted in reduced ES cell proliferation [34]. The activated p-P65 component of the NF-kB pathway was directly related to STAT3; thus, with let-7a inhibition in ES cells, carcinogenic activities of both STAT3 and p-P65 were upregulated [34]. Supporting the oncogenic effects of STAT3 in ES, it has been shown that STAT3 affects the surrounding tumor microenvironment through 
chemokine regulation and generally reduces tumor viability in ES cell lines when inhibited, as investigated by cell viability growth assays [35]. Like MALAT1, STAT3 dysregulation is not unique to ES due to its many roles in proliferation, migration, angiogenesis and microenvironment conditions in a variety cancers, and it is a popular target for a multitude of pharmaceutical inhibitors [36].

\subsection{2. miR-145 and miR-143}

Though several miRNAs are closely related to EWS-FLI1 regulation (let-7g, miR22, miR-30a-5p) [37-39], miR-145 was the sole miRNA identified to directly bind to the $3^{\prime}$-UTR of FLI1 [40]. Consequently, it was seen that the lower levels of miR-145 in ES cells were associated with greater levels of EWS-FLI1 expression. Other targets of miR-145, particularly the ones related to stemness including octamer-binding transcription factor 4 (Oct4), SRY+Box transcription factor 2 (SOX2), Kruppel Like Factor 4 (KLF4) and Myc were also found at higher levels in ES. This indicated that EWS-FLI1 controls both the degree of its autoregulation and these associated oncogenic pathways. Specifically, Oct4 interacts with the Ewing's sarcoma protein EWS directly enhancing differentiation [41], whereas SOX2 enhances proliferation through cell cycle and apoptosis dysregulation [42]. KLF4 remains less studied specifically in ES, but its expression has been observed at higher levels in other cancers like breast and gastrointestinal cancer $[43,44]$. In addition to miR-145, the closely related miR-143 was found to have tumor suppressing roles in ES, targeting the stemness factor Nanog, in addition to those previously listed [45]. Although the exact mechanisms of downregulation of miR143 and miR145 in ES are not well understood, it is speculated that EWSFLI1 is regulating miRNA processing pathways. It was found that expression of miRNA processing enzyme TARBP2 is reduced in ES [45]. Further, treatment with methylation-affecting drugs including 5-Azacytidine (5-AzaC) and 3-deazaneplanocin A (DZNep) returned TARBP2 levels to normal, which simultaneously led to restoration of proper miR maturation functions for miR-143 and miR-145. It has been previously demonstrated that 5-AzaC inhibits DNA methylation and that DZNep inhibits histone methylation [46,47]. Overall, the interaction between these inhibitors and miRNA presents a new and intriguing intersection between clinical level treatments directly affecting the methylation and epigenetics of ES.

\subsection{3. $\mathrm{miR}-124$}

Another critical tumor suppressor miRNA in ES is miR-124. Its downregulation has been shown to cause increased cell growth and motility, increased mesenchymal differentiation and increased invasion [48]. Its targets include snail family transcriptional repressor 2 (SNAI2, also known as SLUG), a suppressor of epithelial markers E-cadherin and $\beta$-catenin, as well as G1 to $S$ cell cycle regulator CCND2. SLUG is related to mesenchymal markers and increased oncogenesis in other cancers such as prostate and breast cancer $[49,50]$. It was also previously discovered that SLUG downregulates E-Cadherin expression and is partly responsible for the cellular transition from epithelium to mesenchymal [51]. More specifically, downregulation of E-Cadherin was observed in ES cell lines and shown to be inversely related to SLUG levels [48]. In accordance with the established cell cycle regulatory role of CCND2, miR-124 upregulation consequently resulted in increased G1-S cell cycle arrest [48]. In vivo studies further confirmed the tumor suppressor role of miR-124 by indicating higher rates of ES metastasis [48]. Interestingly, the epigenetic control by which miRNA suppression is carried out appears similar to that of miR-143 and miR-145. Namely, the drug 5-Aza-CdR was able to recover the expression of miR-124, though it should be noted that direct functional characterization of the miRNA maturation pathway and the exact mechanisms of methylation regulation have not yet been elucidated for miR-124 [48]. Table 1 lists these and other known tumor suppressive miRNAs reported in ES. 
Table 1. MicroRNA in Ewing's Sarcoma with Tumor Suppressor Functions.

\begin{tabular}{|c|c|c|c|c|}
\hline Name & Functions & Pathways & Targets & Citation \\
\hline $\begin{array}{l}\text { Let-7a-2-3p, miR-16-2-3p, } \\
\text { miR-29b-1-5p }\end{array}$ & G0-G1 arrest & c-Myc & CCND2 & [30] \\
\hline Let-7g & Let-7g processing & EWS-FLI1/Drosha & Dicer, CCND1 & [37] \\
\hline miR-22 & $\begin{array}{l}\text { Anchorage dependent growth, } \\
\text { histone methylation }\end{array}$ & EWS-FLI1 & KDM3A & [38] \\
\hline miR-30a-5p & Proliferation, Invasion & EWS-FLI1 & CD99 & [39] \\
\hline miR-143/145 & Stemness & EWS-FLI1 & $\begin{array}{c}\text { FLI1 } \\
\text { Oct4, Sox2, Klf4, Myc, Nanog }\end{array}$ & {$[40,45]$} \\
\hline miR-124 & $\begin{array}{l}\text { Mesenchymal-epithelial markers } \\
\text { G1-S arrest }\end{array}$ & CCND2 & CCND2SLUG & [48] \\
\hline miR-15a & Growth inhibition & $?^{1}$ & CCND1, Bcl-2 & [52] \\
\hline $\mathrm{miR}-21-3 p$ & Proliferation, metastasis & $?^{1}$ & ALCAM/CD166 & [53] \\
\hline miR-27a, miR-100 & General oncogenesis & IGF & IGF-1 & [54] \\
\hline $\operatorname{miR}-125 b$ & General oncogenesis & $\begin{array}{l}\text { IGF } \\
\text { RSK1 }\end{array}$ & IGF-1 & [54] \\
\hline miR-30d & S-phase arrest & MEK/ERK and PI3K/Akt & $\begin{array}{l}\text { MMP-2 } \\
\text { MMP-9 }\end{array}$ & [55] \\
\hline miR-31 & $\begin{array}{l}\text { Proliferation } \\
\text { Invasiveness }\end{array}$ & $?^{1}$ & $?^{1}$ & [56] \\
\hline \multirow[t]{3}{*}{ miR-34a } & Proliferation, chemo-sensitization & P53 & CCND1, Bcl-2 & [57] \\
\hline & Proliferation & $?^{1}$ & CCND1 & [58] \\
\hline & Differentiation & Notch, NF-kB & Notch1, Delta & [59] \\
\hline miR-107 & $\begin{array}{c}\text { Proliferation } \\
\text { Tube formation } \\
\text { Cell cycle arrest } \\
\text { Apoptosis }\end{array}$ & HIF & HIF-1 $\beta$ & [60] \\
\hline miR-124-3p & Cell cycle inhibition & $\begin{array}{l}\text { DLX6-AS1/miR-124- } \\
\text { 3p/CDK4 } \\
\text { axis } \\
\end{array}$ & CDK4 & [61] \\
\hline $\begin{array}{l}\text { miR-124-3p, 139-5p } \\
584-5 p\end{array}$ & Invasion, migration & $?^{1}$ & ROCK1 & [62] \\
\hline miR-125b & Proliferation, migration, invasion & P13K/Akt & PIK3CD & [63] \\
\hline miR-138-1-3p & $\begin{array}{c}\text { Cell cycle repression } \\
\text { Adhesion repression (anoikis) }\end{array}$ & FAK & FAK & [64] \\
\hline miR-185 & Bcl-2Bax & $\begin{array}{l}\text { PI3K/AKT and } \\
\text { Wnt/ } \beta \text {-catenin }\end{array}$ & E2F6 & [65] \\
\hline miR-193b & Anchorage dependent growth & ErbB4 & ErbB4 & [66] \\
\hline miR-199b-5p & $\begin{array}{c}\text { Proliferation, invasion, cell cycle, } \\
\text { apoptosis, } \\
\text { G1-S arrest }\end{array}$ & $?^{1}$ & CCNL1 & [67] \\
\hline miR-638 & $\begin{array}{l}\text { Tube formation } \\
\text { Cell cycle arrest }\end{array}$ & VEGF & VEGFA & [68] \\
\hline miR-708 & DNA repair & EYA chemoresistance & EYA3 & [69] \\
\hline
\end{tabular}

${ }^{1} ?$ = Unknown role. Most studies of tumor suppressor miRNA in ES focused on cell line assays and experiments with the following exceptions being noted: investigations into miR-21-3p and miR-34a used primary tumor data sets [53,57]; miRNA expression can decrease with disease progression (e.g., metastasis) for miR-34a, miR-139-5p and miR-584-5p [58,62]; miRNA expression at other times remain statistically equal across disease progression as in the case of miR-124-3p [62].

\subsection{Oncogenic miRNA}

This class of miRNAs is usually not expressed or expressed at very low level in normal cells. However, the onset of tumorigenic factors leads to an upregulation of these oncogenic miRNAs (oncomiRs). OncomiRs often function by suppressing the expression of tumor suppressor proteins and cell cycle regulators. OncomiRs also generally promote survival of the tumor by enhancing resistance to therapy by downregulating targets involved in 
therapeutic responses [70]. A handful of miRNAs have been reported to play oncogenic roles in ES, which presents a notable contrast to the larger number of tumor suppressive miRNAs. We discuss a few of these key oncomiRs and provide a list of the relevant oncogenic miRNAs reported in ES.

\subsection{1. miR-181c-5p and miR-193a-5p}

Investigation into the oncogenic functions of both miR-181c and miR-193a-5p have revealed that both have varied but interconnected roles in anti-apoptotic mechanisms of ES. Cisplatin treatment appeared to increase the levels of cleaved poly (ADP-ribose) polymerase (PARP), which can be taken as a measure of apoptosis [71,72]. Both of these miRNAs were linked with lower levels of PARP cleavage, suggesting reduced apoptosis, even though their intermediate targets were different; Fas cell surface death receptor (FAS) for miR-181c and trans activating p73 beta (TAp73 $\beta$ ) for miR-193a-5p. FAS requires binding of its ligand for apoptotic activation, but dysfunctional FAS ligand has been previously observed in ES [73,74]. With the addition of this more recent miRNA discovery, it appears multiple mechanisms work to inhibit apoptosis via FAS regulation. Similarly, TAp73 is a known tumor suppressor in other cancers and its downregulation has been linked to increased activity of the NF- $\mathrm{kB}$ pathway in breast cancer as well as increased stem factor expression of Oct4, nanog and SOX2 in carcinoma-like stem cells [75]. Ultimately, both of these miRNAs lead to dysfunction of caspase pathway activity thereby preventing apoptosis and facilitating increased tumor growth $[71,73]$.

\subsection{2. $\mathrm{miR}-210-3 \mathrm{p}$}

MiR-210 was found to directly target and reduce caspase 8 associated protein 2 (CASP8AP2) levels and thus has implications in the FAS pathway as well [76]. In addition to these shared pathways with miR-181c and miR-193a-5p, miR-210 had an interesting role in exosomal miRNA delivery in ES. It was found that a hypoxic tumor microenvironment (TME) increased cancerous sphere formation, and that miR-210 expression was enriched in the hypoxic spheres. This appeared to have a positive feedback mechanism in that miR-210 further promoted the production of spheres [76]. A hypoxic TME promotes the expression of hypoxia-inducible-factor 1 and 2 (HIF1 and HIF2) [77]. It has been suggested that hypoxia generally promotes more aggressive cancer by encouraging metastasis and vascularization through HIF1 and HIF2 but that p53 antagonistic effects adds complexity to the model [78]. Accordingly, HIF1 and HIF2 were found to be elevated by hypoxia in both osteosarcoma (OS) and ES. While apoptosis was enhanced in both cancer cell lines, migration was only enhanced in OS [77]. Clearly, the role of both exosomal miRNA and the hypoxic TME in ES is still a developing field, but such results with miR-210 indicate that there are certainly novel functions to explore in this direction. Table 2 lists these and other oncogenic miRNAs reported in ES.

Table 2. MicroRNAs in Ewing's Sarcoma with Oncogenic Functions.

\begin{tabular}{|c|c|c|c|c|}
\hline Name & Functions & Pathways & Targets & Citation \\
\hline miR-106a 363 & Pro-growth & $?^{1}$ & $?$ & {$[52]$} \\
\hline $\operatorname{miR}-193 a-5 p$ & $\begin{array}{l}\text { Anti-apoptosis, cisplatin } \\
\text { chemoresistance }\end{array}$ & Caspase $3 / 7$, PARP & TAp73ß & [71] \\
\hline miR-181c-5p & Anti-apoptosis & Caspase 3/7/8, PARP & FAS & [73] \\
\hline $\operatorname{miR}-210-3 p$ & $\begin{array}{l}\text { Exosomes in hypoxic TME, sphere } \\
\text { formation, anti-apoptosis }\end{array}$ & FAS and TNF- $\alpha$ & CASP8AP2 & [76] \\
\hline miR-20b-5p & $\begin{array}{l}\text { Cell cycle, Anti-apoptosis, } \\
\text { pro-proliferation }\end{array}$ & TGF- $\beta$, MYC, Smad & TGFBR2 & [79] \\
\hline miR-34b & Pro-growth, migration, invasion & Notch & Notch1 & [80] \\
\hline miR-125b-1, miR-125b-2 & Chemoresistance & p53/Bak & P53, Bak & [81] \\
\hline
\end{tabular}


Table 2. Cont.

\begin{tabular}{cccc}
\hline Name & Functions & Pathways & Targets \\
\hline miR-130b & $\begin{array}{c}\text { Pro-proliferation, invasion, } \\
\text { migration }\end{array}$ & CDC42/PAK1/JNK-AP1 & ARHGAP1 \\
miR-146b-5p & $\begin{array}{c}\text { Pro-proliferation, invasion, } \\
\text { migration }\end{array}$ & $?^{1}$ & BTG2 \\
miR-301a-3p & $\begin{array}{c}\text { G0/G1 checkpoints, } \\
\text { anti-apoptosis, malignancy }\end{array}$ & P13K/Akt & PTEN \\
\hline
\end{tabular}

${ }^{1} ?=$ Unknown role. With the exception of miR-34b, which utilized tissue sample data, other studies investigated oncoMiRs in cell lines [80].

\section{Long Noncoding RNAs}

\subsection{Biogenesis and Function of $\operatorname{lnc} R N A$}

Long noncoding RNAs (lncRNAs) tend to be at least 200 nucleotides long and are one of the many RNA subclasses without a protein-coding potential. They have a variety of functions including chromatin remodeling, translational regulation and gene silencing, among other critical functions which affect a multitude of cellular pathways and protein expression [85]. The range of downstream effects induced by the altered expression of lncRNAs has implications in neuronal disorders such as Huntington's disease and lateral amyotrophic sclerosis, autoimmune conditions, and cancers [86,87]. The biogenesis of lncRNAs is well understood: lncRNAs are transcribed by RNA Polymerase II from poorly conserved regions of the genome, share some of the structural features of mRNAs and may undergo alternative splicing [88]. The characterization of lncRNAs in ES is still in its infancy. There are only a few research articles that identified expression of lncRNAs in ES, and an even smaller fraction of lncRNAs are characterized for their function in ES [85]. Below we discuss the characterized lncRNAs followed by a table of key reported lncRNAs in ES that primarily participate in post transcriptional regulatory mechanisms [85].

\subsubsection{IncRNA EWSAT1}

Long noncoding RNA-227 or lncRNA Ewing Sarcoma-associated transcript 1 (EWSAT1) was the first lncRNA discovered in ES as a result of RNA sequencing analysis. EWSAT1 was found to be upregulated in primary pediatric human mesenchymal progenitor cells which are the likely origin cells for ES development. Evidence indicates that EWSAT1 is a downstream target of the EWS-FLI1 product as EWSAT1 levels were decreased after EWS-FLI-1 knockdown, whereas they are upregulated in ES cell lines. Subsequent EWSAT1 experiments have supported the hypothesis that EWSAT1 promotes proliferation in-vitro, but the mechanisms by which it regulates gene expression are thought to be diverse due to its localization in both the cytoplasm and the nucleus. EWSAT1, which plays a role in the regulation of 404 reported genes, is primarily a mediator of gene repression and has significant overlap in its target genes with the EWS-FLI1 product [89]. Though the identification of this lncRNA's mechanisms in ES cells is a gap in the existing literature, EWSAT1 has since been found to be upregulated in osteosarcoma, cervical cancer, and colorectal cancer among others, in which its suggested mechanism is as a competing endogenous RNA. For example, in colorectal cancer, EWSAT1 sponges miR-326 to upregulate FBXL20 and promote proliferation, migration and invasion [90]. Similarly in osteosarcoma, EWSAT1 sponges miR-24-3p and disrupts the $\mathrm{miR}-24-3 \mathrm{p} / \mathrm{ROCK} 1$ axis to promote metastasis [91].

\subsubsection{IncRNA HULC}

Long noncoding RNA, Highly Upregulated in Liver Cancer (HULC), is a lncRNA which is highly expressed in ES cell lines. Knockdown of HULC significantly hindered ES cell proliferation and clonogenicity; however, apoptosis was not induced. Mechanistically, HULC shares its cytoplasmic localization and suggested function as a competing endogenous RNA with SOX2OT. Several miRNA binding sites within HULC's sequence have been identified, but in-silico analysis has identified miR-186-5p to have the highest binding score [92]. The tumor suppressive miR-186-5p can bind to twist basic helix-loop-helix 
transcription factor 1 (TWIST1) transcripts and inhibit their translation as the two RNAs are negatively correlated [92]. TWIST1 plays a role in ES metastasis, as its suppression reduces metastasis but does not affect the development of the original tumor [93]. HULC's sponging effect on miR-186-5p was established in the evaluation of the small molecule YK4-279, which reduces the transcriptional activity of EWS-FLI1 [94,95]. Treatment of ES cell lines with YK-4-279 downregulated HULC, decreasing its sponging effect on miR-186-5p thereby increasing TWIST1 transcript binding with miR-186-5p and reducing TWIST1 protein levels [92].

\subsubsection{IncRNA SOX2OT}

The lncRNA SOX2OT is a recognized oncogene in many human carcinomas such as colorectal and gastric cancer, and RT-PCR results indicated that SOX2OT transcript expression is also elevated in ES cell lines [96]. SOX2OT is suggested to promote malignant behaviors such as proliferation, cell invasion and survival as these mechanisms were suppressed upon in-vitro transfection of ES cells with si-SOX2OT. SOX2OT is localized in the cytoplasm where it has interplay with miR-363, a miRNA which has suggested anti-carcinogenic effects in other cancers such as gliomas [96]. Another target regulated by SOX2OT is the transcription factor FOXP4 (forkhead box p4) which is involved in several oncogenic axes [97]. Though SOX2OT does not bind directly to FOXP4 mRNA, it modulates the effect of miR-363 on FOXP4 protein expression. Specifically, SOX2OT functions as a competing endogenous lncRNA, sponging miR-363 as supported by luciferase assay results which established the negative correlation between the two noncoding RNAs. Significant upregulation of SOX2OT, as is found clinically in ES samples, decreases miR363 levels and therefore increases FOXP4 protein levels, inducing many downstream malignancy-promoting pathways [98]. A list of these and other lncRNAs studied in ES is provided in Table 3.

Table 3. LncRNA in Ewing's Sarcoma.

\begin{tabular}{|c|c|c|c|c|}
\hline Name & Functions & Pathways & Targets & Citation \\
\hline MALAT1 & $\begin{array}{c}\text { Pro-growth } \\
\text { Pro-proliferation, angiogenesis, migration }\end{array}$ & $\begin{array}{l}\text { SYK/c-MYC/MALAT1 } \\
\text { Hippo }\end{array}$ & EZH2 & [32] \\
\hline lncRNA DLX6-AS1 & $\begin{array}{l}\text { Pro-proliferation, } \\
\text { Pro-cell survival }\end{array}$ & $\begin{array}{l}\text { DLX6-AS1/miR-124- } \\
\text { 3p/CDK4 }\end{array}$ & MiR-124-3p & [61] \\
\hline EWSAT1 & Pro-proliferation & $?^{1}$ & HNRNPK & [89] \\
\hline HULC & $\begin{array}{c}\text { Pro-growth } \\
\text { Chemoresistance } \\
\text { Pro-proliferation }\end{array}$ & $\begin{array}{l}\text { HULC/ miR-186-5p/ } \\
\text { TWIST1 }\end{array}$ & miR-186-5p & [92] \\
\hline $\operatorname{lncSOX} 2 \mathrm{OT}$ & $\begin{array}{c}\text { Metastasis, } \\
\text { Pro-proliferation, invasion, migration }\end{array}$ & $\begin{array}{l}\text { SOX2OT/miR- } \\
\text { 363/FOXP4 }\end{array}$ & $\operatorname{miR}-363$ & [98] \\
\hline pncCCND1_B & $\begin{array}{c}\text { Pro-growth, } \\
\text { Pro-proliferation }\end{array}$ & $?^{1}$ & Sam68 & [99] \\
\hline
\end{tabular}

\section{Future Perspectives}

Consistent with the widespread use of bioinformatic data in the modern scientific enterprise, many papers reviewed had extensive supplementary information regarding more miRNA than were reported here. From differential expression profiles, a subset is investigated further using RNA-seq, and an even smaller subset is chosen as the primary candidates for research papers. Thus, there are a multitude of miRNAs and lncRNAs that have yet to be fully validated for their function in ES.

\subsection{Unexplored Connections}

There currently exist many unexplored connections involving uncharacterized ncRNA and ES. Examples include miRNA dysregulated pathways shared between cancers that cur- 
rently have missing links to ES (Figure 2). For example, the EWS protein is responsible for deregulating metaphase activity in mitosis via an up regulatory interaction with the AuroraB kinase, which is a suspected oncogenic mechanism [100,101]. The tumor suppressor miRNA let-7f was found to target Aurora-B to reduce proliferation, invasion and migration but was only researched in OS [102]. Given that OS is related to ES, it seems plausible that let-7f may be downregulated in ES given a shared mechanism between the two; however, this link has not been reported in the current research. Another example is miR-9-3p, which has been reported to target apoptotic factor Bladder cancer-associated protein (BLCAP) and therefore act as an oncogenic anti-apoptotic driver in thyroid carcinoma [103]. In ES, BLCAP has been shown to be an inducer of apoptosis [104]. Thus, upregulation of miR-9-3p is another hypothetical connection yet to be studied in ES. It is therefore worth to carefully look at ncRNAs identified in other tumors that have implications in shared oncogenic mechanisms but no conclusive links in ES.

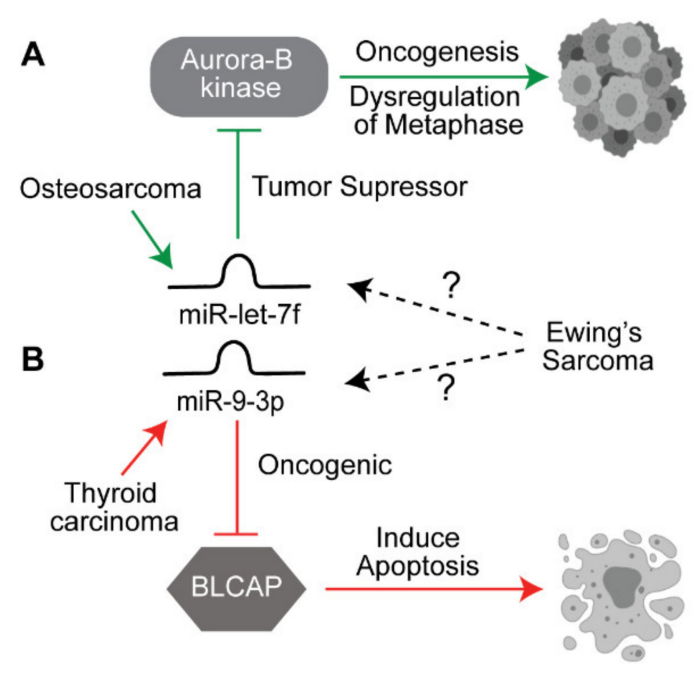

Figure 2. Potential link between miRNAs identified in other cancers. (A) miR-let7f acts as a tumor suppressor miRNA by downregulating the oncogene Aurora B kinase in osteosarcoma. (B) miR-9-3p acts as an oncogenic miRNA by suppressing BLCAP which is required for inducing apoptosis in thyroid cancer. Both of these target genes are similarly affected in ES, but the role of these miRNAs is not yet elucidated in ES. The solid arrows indicate known pathways, the dotted arrows indicate yet to be explored pathways.

\subsection{Biomarkers}

A low expression level of miR-34a has been shown to be correlated with worse ES survival rates [57]. Consistent with this observation, it was found that ES tended to recur in patients with low miR-34a, while higher expression was linked with higher survival rates, reduced relapse and reduced metastasis [58]. Independently, the presence of metastasis at diagnosis was correlated with lower survival rates [105]. Future studies may elucidate if a miRNA differential profile, such as that of miR-34a, precedes traditional clinical diagnoses, which would aid in the delivery of earlier treatment and better outcomes. Further, as the characterization of exosomal RNA cargo (e.g., exosomal miRNAs) is being expanded to various tumors, it is only a matter of time before more regulatory ncRNAs could be identified in the exosomes to serve as non-invasive diagnostic biomarkers to predict the onset, progression, and recurrence of ES.

\subsection{Other Regulatory RNAs}

As mentioned before, no direct studies were found exploring the role of other ncRNAs; however, there is an upcoming interest to explore the vast repertoire of other emerging regulatory RNAs. One of the recently appreciated classes is circular RNAs. CircRNAs are produced by back-splicing events and as their name suggests these are closed ended cova- 
lent circles [106]. CircRNAs are resistant to exonucleases and have emerged as clinically relevant regulatory RNAs in several cancers including osteosarcoma and other pediatric cancers [107]. The role of circRNAs has not been reported in ES directly yet. Though there is one reported circRNA called circEF, an oncogenic fusion associated circRNA, its mechanism of action has not been explored [108]. The major function of circRNAs is to sponge miRNAs and thus regulate mRNA expression [109]. The circRNAs act as the regulator of miRNA-mRNA axes as done by some of the characterized lncRNAs. Furthermore, circRNAs are highly enriched in exosomes making them excellent biomarkers [110]. It is only a matter of time when circRNAs and the other uncharacterized ncRNAs will be explored in ES.

\section{Conclusions}

Noncoding RNAs can act as network modulators, the targets of unidentified lncRNA/circRNA sponge axes or players in yet unidentified cellular roles. The recent appreciation of ncRNA packaging and release via extracellular vesicles has further made these regulatory RNAs key players in maintaining the tumor microenvironment and modulating cell to cell communication. The field of regulatory RNAs is growing exponentially for all tumors, including pediatric sarcomas. Just last month, a new study by Chen et al. used machine learning and training models on existing RNA sequencing data sets from ES patients to identify a set of seven lncRNAs as prognostic risk marker for ES. The increased expression of these seven lncRNAs was statistically correlated with poor overall survival [111]. These seven lncRNA, including SNHG17, WAC-AS1, LINC00623, SSBP3AS1, and TDRG1, are yet to tested experimentally for their association and role in ES, although some have functional roles in other cancers [111]. This study opened a new research direction to explore the use of a set of ncRNAs as prognostic markers. This could potentially also include a set of different regulatory RNAs as a signature for the progress of the disease. In conclusion, this review aimed to provide an assessment of the current landscape of ncRNA, to emphasize the unmet need for research in this field, to explore novel candidates and to characterize the function of existing targets.

Supplementary Materials: The following are available online at https:/ / www.mdpi.com/article / 10.3390/biomedicines9080933/s1, Figure S1: Adapted PRISMA 2020 flow diagram for a review including searches (e.g., "Ewing's sarcoma” + miRNA) of databases only; Table S1: PubMed Keyword Search Totals.

Author Contributions: Conceptualization, M.B. methodology, C.B., A.B. and M.B.; investigation, C.B., A.B., V.P. and M.B.; resources, V.P. and M.B.; data curation, C.B., A.B., V.P. and M.B.; writingoriginal draft preparation, C.B., A.B. and M.B.; writing-review and editing, C.B., A.B., V.P. and M.B., supervision, V.P. and M.B.; project administration, M.B. funding acquisition, V.P. and M.B. All authors have read and agreed to the published version of the manuscript.

Funding: This research was funded by UDRF-SI, grant number 19A00244 to M.B. and NIH-R35, grant number R35GM119504 to V.P. The APC was funded by M.B.

Institutional Review Board Statement: Not applicable.

Informed Consent Statement: Not applicable.

Data Availability Statement: All the data is provided in the manuscript and the supplementary data.

Acknowledgments: We thank the members of Batish laboratory for their assistance and useful discussions.

Conflicts of Interest: The authors declare no conflict of interest. 


\section{References}

1. Ross, K.A.; Smyth, N.A.; Murawski, C.D.; Kennedy, J.G. The Biology of Ewing Sarcoma. ISRN Oncol. 2013, $2013,759725$. [CrossRef]

2. Pinto, A.; Dickman, P.; Parham, D. Pathobiologic Markers of the Ewing Sarcoma Family of Tumors: State of the Art and Prediction of Behaviour. Sarcoma 2011, 2011, 856190. [CrossRef] [PubMed]

3. Burchill, S.A. Ewing's sarcoma: Diagnostic, prognostic, and therapeutic implications of molecular abnormalities. J. Clin. Pathol. 2003, 56, 96-102. [CrossRef] [PubMed]

4. Khan, S.; Abid, Z.; Haider, G.; Bukhari, N.; Zehra, D.; Hashmi, M.; Abid, M.; Ibrahim, U. Incidence of Ewing's Sarcoma in Different Age Groups, Their Associated Features, and Its Correlation With Primary Care Interval. Cureus 2021, 13 , e13986. [CrossRef]

5. Widhe, B.; Widhe, T. Initial Symptoms and Clinical Features in Osteosarcoma and Ewing Sarcoma*. JBJS 2000, 82, 667. [CrossRef]

6. Riggi, N.; Stamenkovic, I. The Biology of Ewing sarcoma. Cancer Lett. 2007, 254, 1-10. [CrossRef]

7. Spahn, L.; Siligan, C.; Bachmaier, R.; Schmid, J.A.; Aryee, D.N.T.; Kovar, H. Homotypic and heterotypic interactions of EWS, FLI1 and their oncogenic fusion protein. Oncogene 2003, 22, 6819-6829. [CrossRef]

8. Tanner, J.M.; Bensard, C.; Wei, P.; Krah, N.M.; Schell, J.C.; Gardiner, J.; Schiffman, J.; Lessnick, S.L.; Rutter, J. EWS/FLI is a Master Regulator of Metabolic Reprogramming in Ewing Sarcoma. Mol. Cancer Res. 2017, 15, 1517-1530. [CrossRef]

9. Markey, F.B.; Carpio, B.; Parashar, V.; Batish, M. Identification of a new transcriptional co-regulator of STEAP1 in Ewing's Sarcoma. Cells 2021, 10, 1300. [CrossRef] [PubMed]

10. May, W.A.; Lessnick, S.L.; Braun, B.S.; Klemsz, M.; Lewis, B.C.; Lunsford, L.B.; Hromas, R.; Denny, C.T. The Ewing's sarcoma EWS/FLI-1 fusion gene encodes a more potent transcriptional activator and is a more powerful transforming gene than FLI-1. Mol. Cell. Biol. 1993, 13, 7393-7398. [CrossRef]

11. Potikyan, G.; France, K.A.; Carlson, M.R.J.; Dong, J.; Nelson, S.F.; Denny, C.T. Genetically defined EWS/FLI1 model system suggests mesenchymal origin of Ewing's family tumors. Lab. Investig. 2008, 88, 1291-1302. [CrossRef]

12. Cidre-Aranaz, F.; Alonso, J. EWS/FLI1 Target Genes and Therapeutic Opportunities in Ewing Sarcoma. Front. Oncol. 2015, 5. [CrossRef]

13. Kovar, H. Blocking the road, stopping the engine or killing the driver? Advances in targeting EWS/FLI-1 fusion in Ewing sarcoma as novel therapy. Expert Opin. Ther. Targets 2014, 18, 1315-1328. [CrossRef] [PubMed]

14. Zhang, Y.; Li, J.; Wang, Y.; Jing, J.; Li, J. The Roles of Circular RNAs in Osteosarcoma. Med. Sci. Monit. Int. Med. J. Exp. Clin. Res. 2019, 25, 6378-6382. [CrossRef] [PubMed]

15. Das, B.; Jain, N.; Mallick, B. piR-39980 promotes cell proliferation, migration and invasion, and inhibits apoptosis via repression of SERPINB1 in human osteosarcoma. Biol. Cell 2020, 112, 73-91. [CrossRef]

16. Zhang, Y.; Qian, H.; He, J.; Gao, W. Mechanisms of tRNA-derived fragments and tRNA halves in cancer treatment resistance. Biomark. Res. 2020, 8, 52. [CrossRef]

17. Zhu, P.; Yu, J.; Zhou, P. Role of tRNA-derived fragments in cancer: Novel diagnostic and therapeutic targets tRFs in cancer. Am. J. Cancer Res. 2020, 10, 393-402.

18. Qin, N.; Ma, Z.; Wang, C.; Zhang, E.; Li, Y.; Huang, M.; Chen, C.; Zhang, C.; Fan, J.; Gu, Y.; et al. Comprehensive characterization of functional eRNAs in lung adenocarcinoma reveals novel regulators and a prognosis-related molecular subtype. Theranostics 2020, 10, 11264-11277. [CrossRef] [PubMed]

19. Gebert, L.F.R.; MacRae, I.J. Regulation of microRNA function in animals. Nat. Rev. Mol. Cell Biol. 2019, 20, 21-37. [CrossRef]

20. Graves, P.; Zeng, Y. Biogenesis of mammalian microRNAs: A global view. Genom. Proteom. Bioinform. 2012, 10, 239-245. [CrossRef]

21. Treiber, T.; Treiber, N.; Meister, G. Regulation of microRNA biogenesis and its crosstalk with other cellular pathways. Nat. Rev. Mol. Cell Biol. 2019, 20, 5-20. [CrossRef] [PubMed]

22. O'Brien, J.; Hayder, H.; Zayed, Y.; Peng, C. Overview of MicroRNA Biogenesis, Mechanisms of Actions, and Circulation. Front. Endocrinol. 2018, 9. [CrossRef] [PubMed]

23. Sempere, L.F.; Freemantle, S.; Pitha-Rowe, I.; Moss, E.; Dmitrovsky, E.; Ambros, V. Expression profiling of mammalian microRNAs uncovers a subset of brain-expressed microRNAs with possible roles in murine and human neuronal differentiation. Genome Biol. 2004, 5, R13. [CrossRef] [PubMed]

24. Yang, Y.; Xu, S.; Xia, L.; Wang, J.; Wen, S.; Jin, P.; Chen, D. The bantam microRNA is associated with drosophila fragile X mental retardation protein and regulates the fate of germline stem cells. PLoS Genet. 2009, 5, e1000444. [CrossRef]

25. Wang, S.; Aurora, A.B.; Johnson, B.A.; Qi, X.; McAnally, J.; Hill, J.A.; Richardson, J.A.; Bassel-Duby, R.; Olson, E.N. The endothelial-specific microRNA miR-126 governs vascular integrity and angiogenesis. Dev. Cell 2008, 15, 261-271. [CrossRef]

26. Yu, Z.; Raabe, T.; Hecht, N.B. MicroRNA Mirn122a Reduces Expression of the Posttranscriptionally Regulated Germ Cell Transition Protein 2 (Tnp2) Messenger RNA (mRNA) by mRNA Cleavage1. Biol. Reprod. 2005, 73, 427-433. [CrossRef] [PubMed]

27. Sasaki, R.; Osaki, M.; Okada, F. MicroRNA-Based Diagnosis and Treatment of Metastatic Human Osteosarcoma. Cancers 2019, 11, 553. [CrossRef] [PubMed]

28. Smolle, M.A.; Leithner, A.; Posch, F.; Szkandera, J.; Liegl-Atzwanger, B.; Pichler, M. MicroRNAs in Different Histologies of Soft Tissue Sarcoma: A Comprehensive Review. Int. J. Mol. Sci. 2017, 18, 1960. [CrossRef] [PubMed]

29. Fujiwara, T.; Kunisada, T.; Takeda, K.; Uotani, K.; Yoshida, A.; Ochiya, T.; Ozaki, T. MicroRNAs in Soft Tissue Sarcomas: Overview of the Accumulating Evidence and Importance as Novel Biomarkers. BioMed Res. Int. 2014, 2014, 592868. [CrossRef] 
30. Kawano, M.; Tanaka, K.; Itonaga, I.; Iwasaki, T.; Tsumura, H. c-Myc Represses Tumor-Suppressive microRNAs, let-7a, miR-16 and miR-29b, and Induces Cyclin D2-Mediated Cell Proliferation in Ewing's Sarcoma Cell Line. PLoS ONE 2015, 10, e0138560. [CrossRef]

31. Collins, K.; Jacks, T.; Pavletich, N.P. The cell cycle and cancer. Proc. Natl. Acad. Sci. USA 1997, 94, 2776-2778. [CrossRef]

32. Sun, H.; Lin, D.-C.; Cao, Q.; Pang, B.; Gae, D.D.; Lee, V.K.M.; Lim, H.J.; Doan, N.; Said, J.W.; Gery, S.; et al. Identification of a Novel SYK/c-MYC/MALAT1 Signaling Pathway and Its Potential Therapeutic Value in Ewing Sarcoma. Clin. Cancer Res. 2017. [CrossRef] [PubMed]

33. Amodio, N.; Raimondi, L.; Juli, G.; Stamato, M.A.; Caracciolo, D.; Tagliaferri, P.; Tassone, P. MALAT1: A druggable long non-coding RNA for targeted anti-cancer approaches. J. Hematol. Oncol. 2018, 11, 63. [CrossRef]

34. Zhang, Z.; Li, Y.; Huang, L.; Xiao, Q.; Chen, X.; Zhong, J.; Chen, Y.; Yang, D.; Han, Z.; Shu, Y.; et al. Let-7a suppresses macrophage infiltrations and malignant phenotype of Ewing sarcoma via STAT3/NF-kB positive regulatory circuit. Cancer Lett. 2016, 374, 192-201. [CrossRef]

35. Behjati, S.; Basu, B.P.; Wallace, R.; Bier, N.; Sebire, N.; Hasan, F.; Anderson, J. STAT3 Regulates Proliferation and Immunogenicity of the Ewing Family of Tumors In Vitro. Sarcoma 2012, 2012, 987239. [CrossRef]

36. Kamran, M.Z.; Patil, P.; Gude, R.P. Role of STAT3 in Cancer Metastasis and Translational Advances. BioMed Res. Int. 2013, 2013, 421821. [CrossRef]

37. Sohn, E.J.; Park, J.; Kang, S.-I.; Wu, Y.-P. Accumulation of pre-let-7g and downregulation of mature let-7g with the depletion of EWS. Biochem. Biophys. Res. Commun. 2012, 426, 89-93. [CrossRef]

38. Parrish, J.K.; Sechler, M.; Winn, R.A.; Jedlicka, P. The histone demethylase KDM3A is a microRNA-22-regulated tumor promoter in Ewing Sarcoma. Oncogene 2015, 34, 257-262. [CrossRef]

39. Franzetti, G.A.; Laud-Duval, K.; Bellanger, D.; Stern, M.H.; Sastre-Garau, X.; Delattre, O. MiR-30a-5p connects EWS-FLI1 and CD99, two major therapeutic targets in Ewing tumor. Oncogene 2013, 32, 3915-3921. [CrossRef]

40. Ban, J.; Jug, G.; Mestdagh, P.; Schwentner, R.; Kauer, M.; Aryee, D.N.T.; Schaefer, K.L.; Nakatani, F.; Scotlandi, K.; Reiter, M.; et al. Hsa-mir-145 is the top EWS-FLI1-repressed microRNA involved in a positive feedback loop in Ewing's sarcoma. Oncogene 2011, 30, 2173-2180. [CrossRef]

41. Lee, J.; Rhee, B.K.; Bae, G.-Y.; Han, Y.-M.; Kim, J. Stimulation of Oct-4 Activity by Ewing's Sarcoma Protein. Stem Cells 2005, 23, 738-751. [CrossRef] [PubMed]

42. Ren, C.; Ren, T.; Yang, K.; Wang, S.; Bao, X.; Zhang, F.; Guo, W. Inhibition of SOX2 induces cell apoptosis and G1/S arrest in Ewing's sarcoma through the PI3K/Akt pathway. J. Exp. Clin. Cancer Res. 2016, 35, 44. [CrossRef]

43. Yu, F.; Li, J.; Chen, H.; Fu, J.; Ray, S.; Huang, S.; Zheng, H.; Ai, W. Kruppel-like factor 4 (KLF4) is required for maintenance of breast cancer stem cells and for cell migration and invasion. Oncogene 2011, 30, 2161-2172. [CrossRef]

44. Wei, D.; Kanai, M.; Huang, S.; Xie, K. Emerging role of KLF4 in human gastrointestinal cancer. Carcinogenesis 2005, $27,23-31$. [CrossRef] [PubMed]

45. De Vito, C.; Riggi, N.; Cornaz, S.; Suvà, M.-L.; Baumer, K.; Provero, P.; Stamenkovic, I. A TARBP2-Dependent miRNA Expression Profile Underlies Cancer Stem Cell Properties and Provides Candidate Therapeutic Reagents in Ewing Sarcoma. Cancer Cell 2012, 21, 807-821. [CrossRef]

46. Christman, J.K. 5-Azacytidine and 5-aza-2'-deoxycytidine as inhibitors of DNA methylation: Mechanistic studies and their implications for cancer therapy. Oncogene 2002, 21, 5483-5495. [CrossRef]

47. Miranda, T.B.; Cortez, C.C.; Yoo, C.B.; Liang, G.; Abe, M.; Kelly, T.K.; Marquez, V.E.; Jones, P.A. DZNep is a global histone methylation inhibitor that reactivates developmental genes not silenced by DNA methylation. Mol. Cancer Ther. 2009, 8, 1579-1588. [CrossRef]

48. Li, Y.; Shao, G.; Zhang, M.; Zhu, F.; Zhao, B.; He, C.; Zhang, Z. miR-124 represses the mesenchymal features and suppresses metastasis in Ewing sarcoma. Oncotarget 2016, 8, 10274. [CrossRef]

49. Emadi Baygi, M.; Soheili, Z.-S.; Essmann, F.; Deezagi, A.; Engers, R.; Goering, W.; Schulz, W.A. Slug/SNAI2 regulates cell proliferation and invasiveness of metastatic prostate cancer cell lines. Tumor Biol. 2010, 31, 297-307. [CrossRef]

50. Alves, C.L.; Elias, D.; Lyng, M.B.; Bak, M.; Ditzel, H.J. SNAI2 upregulation is associated with an aggressive phenotype in fulvestrant-resistant breast cancer cells and is an indicator of poor response to endocrine therapy in estrogen receptor-positive metastatic breast cancer. Breast Cancer Res. 2018, 20, 60. [CrossRef]

51. Bolós, V.; Peinado, H.; Pérez-Moreno, M.A.; Fraga, M.F.; Esteller, M.; Cano, A. The transcription factor Slug represses E-cadherin expression and induces epithelial to mesenchymal transitions: A comparison with Snail and E47 repressors. J. Cell Sci. 2003, 116, 499-511. [CrossRef]

52. Dylla, L.; Jedlicka, P. Growth-Promoting Role of the miR-106a 363 Cluster in Ewing Sarcoma. PLoS ONE 2013,8 , e63032. [CrossRef]

53. Liu, Y.; Chen, G.; Liu, H.; Li, Z.; Yang, Q.; Gu, X.; Du, Z.; Zhang, G.; Wang, J. Integrated bioinformatics analysis of miRNA expression in Ewing sarcoma and potential regulatory effects of miR-21 via targeting ALCAM/CD166. Artif. Cells Nanomed. Biotechnol. 2019, 47, 2114-2122. [CrossRef]

54. McKinsey, E.L.; Parrish, J.K.; Irwin, A.E.; Niemeyer, B.F.; Kern, H.B.; Birks, D.K.; Jedlicka, P. A novel oncogenic mechanism in Ewing sarcoma involving IGF pathway targeting by EWS/Fli1-regulated microRNAs. Oncogene 2011, 30, 4910-4920. [CrossRef] [PubMed] 
55. Ye, C.; Yu, X.; Liu, X.; Dai, M.; Zhang, B. miR-30d inhibits cell biological progression of Ewing's sarcoma by suppressing the MEK/ERK and PI3K/Akt pathways in vitro Corrigendum in /10.3892/ol.2020.12394. Oncol. Lett. 2018, 15, 4390-4396. [CrossRef]

56. Karnuth, B.; Dedy, N.; Spieker, T.; Lawlor, E.R.; Gattenlöhner, S.; Ranft, A.; Dirksen, U.; Jürgens, H.; Bräuninger, A. Differentially Expressed miRNAs in Ewing Sarcoma Compared to Mesenchymal Stem Cells: Low miR-31 Expression with Effects on Proliferation and Invasion. PLoS ONE 2014, 9, e93067. [CrossRef]

57. Nakatani, F.; Ferracin, M.; Manara, M.C.; Ventura, S.; del Monaco, V.; Ferrari, S.; Alberghini, M.; Grilli, A.; Knuutila, S.; Schaefer, K.-L.; et al. miR-34a predicts survival of Ewing's sarcoma patients and directly influences cell chemo-sensitivity and malignancy. J. Pathol. 2012, 226, 796-805. [CrossRef] [PubMed]

58. Marino, M.T.; Grilli, A.; Baricordi, C.; Manara, M.C.; Ventura, S.; Pinca, R.S.; Bellenghi, M.; Calvaruso, M.; Mattia, G.; Donati, D.; et al. Prognostic significance of miR-34a in Ewing sarcoma is associated with cyclin D1 and ki-67 expression. Ann. Oncol. 2014, 25, 2080-2086. [CrossRef]

59. Ventura, S.; Aryee, D.N.T.; Felicetti, F.; De Feo, A.; Mancarella, C.; Manara, M.C.; Picci, P.; Colombo, M.P.; Kovar, H.; Carè, A.; et al. CD99 regulates neural differentiation of Ewing sarcoma cells through miR-34a-Notch-mediated control of NF- $\mathrm{B}$ signaling. Oncogene 2016, 35, 3944-3954. [CrossRef] [PubMed]

60. Chen, J.; Zhou, X.; Xiao, Q.; Wang, T.; Shao, G.; Li, Y.; Zhang, Z. MiR-107 suppresses cell proliferation and tube formation of Ewing sarcoma cells partly by targeting HIF-1ß. Hum. Cell 2018, 31, 42-49. [CrossRef]

61. Lei, X.; Yang, S.; Yang, Y.; Zhang, J.; Wang, Y.; Cao, M. Long noncoding RNA DLX6-AS1 targets miR-124-3p/CDK4 to accelerate Ewing's sarcoma. Am. J. Transl. Res. 2019, 11, 6569-6576. [PubMed]

62. Roberto, G.M.; Delsin, L.E.A.; Vieira, G.M.; Silva, M.O.; Hakime, R.G.; Gava, N.F.; Engel, E.E.; Scrideli, C.A.; Tone, L.G.; Brassesco, M.S. ROCK1-PredictedmicroRNAs Dysregulation Contributes to Tumor Progression in Ewing Sarcoma. Pathol. Oncol. Res. 2020, 26, 133-139. [CrossRef] [PubMed]

63. Li, J.; You, T.; Jing, J. MiR-125b inhibits cell biological progression of Ewing's sarcoma by suppressing the PI3K/Akt signalling pathway. Cell Prolif. 2014, 47, 152-160. [CrossRef]

64. Tanaka, K.; Kawano, M.; Itonaga, I.; Iwasaki, T.; Miyazaki, M.; Ikeda, S.; Tsumura, H. Tumor suppressive microRNA-138 inhibits metastatic potential via the targeting of focal adhesion kinase in Ewing's sarcoma cells. Int. J. Oncol. 2016, 48, 1135-1144. [CrossRef]

65. Zhang, S.; Li, D.; Jiao, G.-J.; Wang, H.-L.; Yan, T.-B. miR-185 suppresses progression of Ewing's sarcoma via inhibiting the PI3K/AKT and Wnt/ $\beta$-catenin pathways. OncoTargets Ther. 2018, 11, 7967-7977. [CrossRef]

66. Moore, C.; Parrish, J.K.; Jedlicka, P. MiR-193b, downregulated in Ewing Sarcoma, targets the ErbB4 oncogene to inhibit anchorageindependent growth. PLoS ONE 2017, 12, e0178028. [CrossRef]

67. Li, W.; Li, Y.; Guo, J.; Pan, H.; Zhang, Y.; Wang, X. Overexpression of miR-199b-5p inhibits Ewing's sarcoma cell lines by targeting CCNL1. Mol. Med. Rep. 2015, 12, 3359-3364. [CrossRef]

68. Zhou, X.; Chen, J.; Xiao, Q.; Wang, T.; Yu, Y.; Li, B.; Shao, G.; Li, Y.; Zhang, Z. MicroRNA-638 inhibits cell growth and tubule formation by suppressing VEGFA expression in human Ewing sarcoma cells. Biosci. Rep. 2018, 38, BSR20171017. [CrossRef]

69. Robin, T.P.; Smith, A.; McKinsey, E.; Reaves, L.; Jedlicka, P.; Ford, H.L. EWS/FLI1 Regulates EYA3 in Ewing Sarcoma via Modulation of miRNA-708, Resulting in Increased Cell Survival and Chemoresistance. Mol. Cancer Res. 2012, 10, 1098-1108. [CrossRef]

70. Garzon, R.; Marcucci, G.; Croce, C.M. Targeting microRNAs in cancer: Rationale, strategies and challenges. Nat. Rev. Drug Discov. 2010, 9, 775-789. [CrossRef] [PubMed]

71. Jacques, C.; Calleja, L.R.; Baud'huin, M.; Quillard, T.; Heymann, D.; Lamoureux, F.; Ory, B. miRNA-193a-5p repression of p73 controls Cisplatin chemoresistance in primary bone tumors. Oncotarget 2016, 7, 54503. [CrossRef] [PubMed]

72. Gobeil, S.; Boucher, C.C.; Nadeau, D.; Poirier, G.G. Characterization of the necrotic cleavage of poly(ADP-ribose) polymerase (PARP-1): Implication of lysosomal proteases. Cell Death Differ. 2001, 8, 588-594. [CrossRef]

73. Kawano, M.; Tanaka, K.; Itonaga, I.; Iwasaki, T.; Tsumura, H. MicroRNA-181c prevents apoptosis by targeting of FAS receptor in Ewing's sarcoma cells. Cancer Cell Int. 2018, 18, 37. [CrossRef]

74. Kontny, H.U.; Lehrnbecher, T.M.; Chanock, S.J.; Mackall, C.L. Simultaneous Expression of Fas and Nonfunctional Fas Ligand in Ewing's Sarcoma. Cancer Res. 1998, 58, 5842-5849. [PubMed]

75. Wolfsberger, J.; Sakil, H.A.M.; Zhou, L.; van Bree, N.; Baldisseri, E.; de Souza Ferreira, S.; Zubillaga, V.; Stantic, M.; Fritz, N.; Hartman, J.; et al. TAp73 represses NF-kB-mediated recruitment of tumor-associated macrophages in breast cancer. Proc. Natl. Acad. Sci. USA 2021, 118, e2017089118. [CrossRef] [PubMed]

76. Kling, M.J.; Chaturvedi, N.K.; Kesherwani, V.; Coulter, D.W.; McGuire, T.R.; Sharp, J.G.; Joshi, S.S. Exosomes secreted under hypoxia enhance stemness in Ewing's sarcoma through miR-210 delivery. Oncotarget 2020, 11, 3633. [CrossRef]

77. Knowles, H.J.; Schaefer, K.-L.; Dirksen, U.; Athanasou, N.A. Hypoxia and hypoglycaemia in Ewing's sarcoma and osteosarcoma: Regulation and phenotypic effects of Hypoxia-Inducible Factor. BMC Cancer 2010, 10, 372. [CrossRef]

78. Petrova, V.; Annicchiarico-Petruzzelli, M.; Melino, G.; Amelio, I. The hypoxic tumour microenvironment. Oncogenesis 2018, 7, 10. [CrossRef]

79. Kawano, M.; Tanaka, K.; Itonaga, I.; Iwasaki, T.; Tsumura, H. MicroRNA-20b promotes cell proliferation via targeting of TGF- $\beta$ receptor II and upregulates MYC expression in Ewing's sarcoma cells. Int. J. Oncol. 2017, 51, 1842-1850. [CrossRef] 
80. Lu, Q.; Lu, M.; Li, D.; Zhang, S. MicroRNA-34b promotes proliferation, migration and invasion of Ewing's sarcoma cells by downregulating Notch1. Mol. Med. Rep. 2018, 18, 3577-3588. [CrossRef]

81. Iida, K.; Fukushi, J.-i.; Matsumoto, Y.; Oda, Y.; Takahashi, Y.; Fujiwara, T.; Fujiwara-Okada, Y.; Hatano, M.; Nabashima, A.; Kamura, S.; et al. miR-125b develops chemoresistance in Ewing sarcoma/primitive neuroectodermal tumor. Cancer Cell Int. 2013, 13, 21. [CrossRef]

82. Satterfield, L.; Shuck, R.; Kurenbekova, L.; Allen-Rhoades, W.; Edwards, D.; Huang, S.; Rajapakshe, K.; Coarfa, C.; Donehower, L.A.; Yustein, J.T. miR-130b directly targets ARHGAP1 to drive activation of a metastatic CDC42-PAK1-AP1 positive feedback loop in Ewing sarcoma. Int. J. Cancer 2017, 141, 2062-2075. [CrossRef] [PubMed]

83. Qu, L.; Zhang, W.; Li, J.; Liu, P. The miR-146b-5p promotes Ewing's sarcoma cells progression via suppressing the expression of BTG2. Sci. Prog. 2021, 104, 1-16. [CrossRef]

84. Kawano, M.; Tanaka, K.; Itonaga, I.; Iwasaki, T.; Tsumura, H. MicroRNA-301a promotes cell proliferation via PTEN targeting in Ewing's sarcoma cells. Int. J. Oncol. 2016, 48, 1531-1540. [CrossRef]

85. Statello, L.; Guo, C.-J.; Chen, L.-L.; Huarte, M. Gene regulation by long non-coding RNAs and its biological functions. Nat. Rev. Mol. Cell Biol. 2021, 22, 96-118. [CrossRef] [PubMed]

86. Wei, C.-W.; Luo, T.; Zou, S.-S.; Wu, A.-S. The Role of Long Noncoding RNAs in Central Nervous System and Neurodegenerative Diseases. Front. Behav. Neurosci. 2018, 12. [CrossRef]

87. Huarte, M. The emerging role of lncRNAs in cancer. Nat. Med. 2015, 21, 1253-1261. [CrossRef]

88. Gonzalez, I.; Munita, R.; Agirre, E.; Dittmer, T.A.; Gysling, K.; Misteli, T.; Luco, R.F. A lncRNA regulates alternative splicing via establishment of a splicing-specific chromatin signature. Nat. Struct. Mol. Biol. 2015, 22, 370-376. [CrossRef] [PubMed]

89. Marques Howarth, M.; Simpson, D.; Ngok, S.P.; Nieves, B.; Chen, R.; Siprashvili, Z.; Vaka, D.; Breese, M.R.; Crompton, B.D.; Alexe, G.; et al. Long noncoding RNA EWSAT1-mediated gene repression facilitates Ewing sarcoma oncogenesis. J. Clin. Investig. 2014, 124, 5275-5290. [CrossRef]

90. Liu, J.; Huang, S.; Liao, X.; Chen, Z.; Li, L.; Yu, L.; Zhan, W.; Li, R. LncRNA EWSAT1 Promotes Colorectal Cancer Progression Through Sponging miR-326 to Modulate FBXL20 Expression. Oncotargets Ther. 2021, 14, 367-378. [CrossRef] [PubMed]

91. Shen, D.; Liu, Y.; Liu, Y.; Wang, T.; Yuan, L.; Huang, X.; Wang, Y. Long non-coding RNA EWSAT1 promoted metastasis and actin cytoskeleton changes via miR-24-3p sponging in osteosarcoma. J. Cell. Mol. Med. 2021, 25, 716-728. [CrossRef]

92. Mercatelli, N.; Fortini, D.; Palombo, R.; Paronetto, M.P. Small molecule inhibition of Ewing sarcoma cell growth via targeting the long non coding RNA HULC. Cancer Lett. 2020, 469, 111-123. [CrossRef]

93. Choo, S.; Wang, P.; Newbury, R.; Roberts, W.; Yang, J. Reactivation of TWIST1 contributes to Ewing sarcoma metastasis. Pediatr Blood Cancer 2018, 65, e26721. [CrossRef] [PubMed]

94. Barber-Rotenberg, J.S.; Selvanathan, S.P.; Kong, Y.; Erkizan, H.V.; Snyder, T.M.; Hong, S.P.; Kobs, C.L.; South, N.L.; Summer, S.; Monroe, P.J.; et al. Single enantiomer of YK-4-279 demonstrates specificity in targeting the oncogene EWS-FLI1. Oncotarget 2012, 3, 172-182. [CrossRef] [PubMed]

95. Lamhamedi-Cherradi, S.E.; Menegaz, B.A.; Ramamoorthy, V.; Aiyer, R.A.; Maywald, R.L.; Buford, A.S.; Doolittle, D.K.; Culotta, K.S.; O'Dorisio, J.E.; Ludwig, J.A. An Oral Formulation of YK-4-279: Preclinical Efficacy and Acquired Resistance Patterns in Ewing Sarcoma. Mol. Cancer Ther. 2015, 14, 1591-1604. [CrossRef]

96. Conti, A.; Romeo, S.G.; Cama, A.; La Torre, D.; Barresi, V.; Pezzino, G.; Tomasello, C.; Cardali, S.; Angileri, F.F.; Polito, F.; et al. MiRNA expression profiling in human gliomas: Upregulated miR-363 increases cell survival and proliferation. Tumor Biol. 2016, 37, 14035-14048. [CrossRef] [PubMed]

97. Yin, Z.; Ding, H.; He, E.; Chen, J.; Li, M. Up-regulation of microRNA-491-5p suppresses cell proliferation and promotes apoptosis by targeting FOXP4 in human osteosarcoma. Cell Prolif. 2017, 50, e12308. [CrossRef]

98. Ma, L.; Sun, X.; Kuai, W.; Hu, J.; Yuan, Y.; Feng, W.; Lu, X. LncRNA SOX2 overlapping transcript acts as a miRNA sponge to promote the proliferation and invasion of Ewing's sarcoma. Am. J. Transl. Res. 2019, 11, 3841-3849. [PubMed]

99. Palombo, R.; Frisone, P.; Fidaleo, M.; Mercatelli, N.; Sette, C.; Paronetto, M.P. The Promoter-Associated Noncoding RNA pncCCND1_B Assembles a Protein-RNA Complex to Regulate Cyclin D1 Transcription in Ewing Sarcoma. Cancer Res. 2019, 79, 3570-3582. [CrossRef]

100. Park, H.; Turkalo, T.K.; Nelson, K.; Folmsbee, S.S.; Robb, C.; Roper, B.; Azuma, M. Ewing sarcoma EWS protein regulates midzone formation by recruiting Aurora B kinase to the midzone. Cell Cycle 2014, 13, 2391-2399. [CrossRef]

101. Wakahara, K.; Ohno, T.; Kimura, M.; Masuda, T.; Nozawa, S.; Dohjima, T.; Yamamoto, T.; Nagano, A.; Kawai, G.; Matsuhashi, A.; et al. EWS-Fli1 Up-Regulates Expression of the Aurora A and Aurora B Kinases. Mol. Cancer Res. 2008, 6, 1937-1945. [CrossRef]

102. Chen, G.; Gu, H.; Fang, T.; Zhou, K.; Xu, J.; Yin, X. Hypoxia-induced let-7f-5p/TARBP2 feedback loop regulates osteosarcoma cell proliferation and invasion by inhibiting the Wnt signaling pathway. Aging 2020, 12, 6891-6903. [CrossRef]

103. Chen, Y.; Zhang, S.; Zhao, R.; Zhao, Q.; Zhang, T. Upregulated miR-9-3p Promotes Cell Growth and Inhibits Apoptosis in Medullary Thyroid Carcinoma by Targeting BLCAP. Oncol. Res. 2017, 25, 1215-1222. [CrossRef] [PubMed]

104. Fan, D.-G.; Zhao, F.; Ding, Y.; Wu, M.-M.; Fan, Q.-Y.; Shimizu, K.; Dohjima, T.; Nozawa, S.; Wakahara, K.; Ohno, T.; et al. BLCAP induces apoptosis in human Ewing's sarcoma cells. Exp. Biol. Med. 2011, 236, 1030-1035. [CrossRef]

105. López Guerra, J.L.; Márquez-Vega, C.; Ramírez-Villar, G.L.; Cabrera, P.; Ordóñez, R.; Praena-Fernández, J.M.; Ortiz, M.J. Prognostic factors for overall survival in paediatric patients with Ewing sarcoma of bone treated according to multidisciplinary protocol. Clin. Transl. Oncol. 2012, 14, 294-301. [CrossRef] 
106. Liu, J.; Liu, T.; Wang, X.; He, A. Circles reshaping the RNA world: From waste to treasure. Mol. Cancer 2017, 16, 58. [CrossRef] [PubMed]

107. Liu, J.; Yang, L.; Fu, Q.; Liu, S. Emerging Roles and Potential Biological Value of CircRNA in Osteosarcoma. Front. Oncol. 2020, 10, 552236. [CrossRef] [PubMed]

108. Guarnerio, J.; Bezzi, M.; Jeong, J.C.; Paffenholz, S.V.; Berry, K.; Naldini, M.M.; Lo-Coco, F.; Tay, Y.; Beck, A.H.; Pandolfi, P.P. Oncogenic Role of Fusion-circRNAs Derived from Cancer-Associated Chromosomal Translocations. Cell 2016, 166, $1055-1056$. [CrossRef]

109. Panda, A.C. Circular RNAs Act as miRNA Sponges. Adv. Exp. Med. Biol. 2018, 1087, 67-79. [CrossRef]

110. Li, Y.; Zheng, Q.; Bao, C.; Li, S.; Guo, W.; Zhao, J.; Chen, D.; Gu, J.; He, X.; Huang, S. Circular RNA is enriched and stable in exosomes: A promising biomarker for cancer diagnosis. Cell Res. 2015, 25, 981-984. [CrossRef]

111. Chen, Z.; Wang, X.; Wang, G.; Xiao, B.; Ma, Z.; Huo, H.; Li, W. A seven-lncRNA signature for predicting Ewing's sarcoma. PeerJ 2021, 9, e11599. [CrossRef] [PubMed] 